\title{
Apartment project risk assessment under market uncertainty; a case study in Wonokromo, Surabaya
}

\author{
Aditya Sutantio ${ }^{1, *}$, I Putu Artama Wiguna ${ }^{2}$,Tri Joko Wahyu $\mathrm{Adi}^{2}$ \\ ${ }^{1}$ Postgraduate Program, Civil Engineering, Institut Teknologi Sepuluh Nopember (ITS), Surabaya 60111 Indonesia \\ ${ }^{2}$ Civil Engineering, Institut Teknologi Sepuluh Nopember (ITS), Surabaya 60111 Indonesia
}

\begin{abstract}
Apartment projects are developed based on a set of assumptions; therefore they have to face risks and uncertainties. One of the most important risks is the uncertainty of the market. The economic condition that causes market slow-down in Indonesia recently has led to some certain of stagnation of apartment development, of which impacts remain for years. In such condition, it is necessary to understand how to measure risks before making a decision. The objective of this paper is to assess risk in apartment project under market uncertainty, using quantitative tools selected from the theory associated with the investment decision. The parameters are market risks and operating risks. Market risk is subdivided into capital market risk(CMr), valuation risk ( $\mathrm{Vr}$ ) and market growth rate risk (MGRr), while real estate operating risk is subdivided into operating risk (Or), development risk (Dr), leasing risk ( $\mathrm{Lr}$ ), leasehold risk (LHr) and leverage risk (LVr). The riskiness values are categorized into three classes: conservative, moderate and aggressive. A leased apartment development project in Wonokromo, Surabaya was selected as a case study. The project covered 8,773 square meters of land and consisted of one tower with total 31,829 square meters gross floor area, equipped with parking lots and amenities. The study found out that The $\mathrm{CMr}$ was $36 \% \mathrm{Vr}$ was $13 \%$, MGRr was $50 \%$, Or was $112 \%$, Dr was $47 \%$, Lr was $215 \%$, LHr was $61 \%$ and LVr was $156 \%$. Although the overall project risk values lie in conservative category, since the level of leasing risk is in aggresive range, more comprehensive investigation should be carried out during a decision-making to reduce the negative impact of risks.
\end{abstract}

\section{Introduction}

Property sector, and apartment projects in particular, had been experiencing tough years during 2007-2009, soon after the eruption of 2006 financial crisis in The United States. It was triggered by subprime mortgage crisis which spread globally and resulting in property turbulence, insolvent mortgages, and price bubble [1]. The burst of the subprime mortgage crisis was followed by the decision of some banks to freeze the price of their investment funds, raising the interest rates and suspending sale to prevent depreciation. Indonesia is not an exception. The surveys conducted periodically by The Indonesia Central Bank (Bank Indonesia) showed that in the first three months of 2009, property sales decreased by minus $4,21 \%$ y.o.y (year on year) from the previous year [2] whereas in Surabaya the residential index was going down to $3,64 \%$, comparing to average of $4,52 \%$ in the previous year. The slow-down continued until the third quarter of 2009 when the banks started to lower their mortgage rate policy from the average of $14 \%$ during the crisis. In this regard, one puzzling evidence in the residential housing market is that, on the one hand, potential buyers are reluctant to buy because of the lack of financial resources and the credit crunch, but on the other hand owners are reluctant to sell due to the so-called "hold out phenomenon". As a consequence trading volume is low under a declining market. This decrease is attributable to both supply and demand factors. Demand factors are mainly related to the weakness and decline of the housing market and the negative phase of the economic cycle, characterized by an increase in the unemployment rate and the reduction in household incomes. Supply factors are mainly related to both the "hold out phenomenon" which have been previously mentioned and the deterioration in loan quality independently of a rise in official interest rates [3].

The above phenomenon raised concerns about economic overheating that might strongly impact the property market, causing the next turn down. It was then proven when the residential market especially condominium in Jakarta slipped to 2,58 \% q.o.q (quarter on quarter) and 3,93\% y.o.y [4] with quite less supply since 2013. As we might acknowledge, it continued until 2015 .

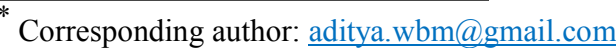


Residential development is a multiphase process; it starts with land development, followed by residential development and ends with the marketing phase - the sale or leasing of the completed site. Risks and uncertainties always occur in real estate development projects, particularly in the complicated residential project. Each stage involves various risks which are differently allocated between landowners, land developers, and home builders [5]. Therefore, they expect an effective allocation and use of capital and they need to know how to measure risk and understand the correlation between risk borne and risk premiums. As the creation of real estate products is in many cases speculative and therefore in anticipation of an unknown future demand, risk and uncertainty are key elements of real estate development [6]. It is a safe assumption that organisations as well as individual investors, which are able to demonstrate that they are aware of their risks and manage opportunities and threats in an entrepreneurial and effective manner, are able to inspire confidence among their stakeholders including any other business partners who are more likely to consider an organisation managed in a risk-aware manner as being investment-worthy.

In order to estimate discount rates and return for residential development, first of all the investors need to know how to measure risks, how much risk they can tolerate, the return they need and its timing. The issue of identifying and assessing risk and uncertainty in the property valuations is one of the key concerns in contemporary literature [7]. It is argued that risk and uncertainty are inherent parts of the valuation process because the investors are unable to specify and price accurately all current and future influences on the value of the asset [8].

Residential development is also a dynamic process involving almost all disciplines where each stage encounters various risks allocating between stakeholders as agents who have a high level of engagement, therefore they become one of the key success factor [7]. In regard to the issue, this paper discusses an operational approach to address risk under unexpected circumstances, that aims to encourage the use of understandable analytical tools in assessing risks by researchers as well as practitioners.

The main objective of this paper is to provide risk assessment tools to addressing risk and uncertainty in residential investment decision in times of economic volatility, and to enrich the understanding of risk management and risk assessment in particular, in residential development industry, by conducting empirical research in apartment development project in Surabaya.

\section{Literatur Review}

Risk is a concept that can be broadly defined and can be applied in numerous situations. If not mentioned otherwise, the term risk used within this paper refers to the property investment risk "as the probability that a target rate of return will not be realized" [8]. There are several studies which explain economical risks with respect to investment decision in residential project. O. Armaneri, G. Ozdagoglu and O. Yalcinkaya [9] have discussed an approach in project risk assessment using integrative decision support for project investors in risky and uncertain environments. As generally accepted, in a relatively normal situation, the process of project evaluation mostly used net present value (NPV), which is calculated based on certain criteria. The value of a risky project parameter is unknown until the event occurs, but the probability that the project parameter will have a specific value may be known. From this point of view, the risky project parameters can be defined as random variables and expressed as probability distributions. On the other hand, in uncertain environments, it is not possible to utilize probabilities for future random events. While probability theory can be a powerful tool in the appropriate circumstances, sometimes the type of uncertainty encountered in investment projects does not fit the axiomatic basis of probability theory. It is simply because that uncertainty in the projects is usually caused by the inherent fuzziness of the parameter estimate rather than randomness [10]. Because project uncertainty parameters can be so difficult to be estimated accurately, it was advised to consider a range of possible values for cash flow elements. If a range of values for individual project parameters is possible, it follows that a range of values for the NPV of a given project is also possible. It can be said that, the term project risk is used to refer to variability in a project's NPV. A greater project risk means a greater variability in a project's NPV [11]. In this regard, instead of using the traditional NPV formulation, they proposed a modified NPV as follows [9]:

$$
\mathrm{NPV}=\sum_{i=1}^{N} \quad \frac{\left[A_{t}(1+x e)^{t}-I_{t}(1+y e)^{t}\right](1-\mathrm{V})+D_{t} \mathrm{~V}}{(1+i)^{t}}-I o
$$

where $\mathrm{V}$ represents the tax rate, and $\mathrm{D}_{t}$ represents the depreciation rate at $t$ th period.

In this paper we take two significant risks using risk classification standard provided by The European Group of Valuers' Association which is utilized by European Union to valuate real estate markets which are closely dependent on bank finance, and therefore affected by the crisis. The assessment tools are shown in Table 1 [7] [12].

Table 1. Risk Classification.

\begin{tabular}{|c|l|l|}
\hline Classification & \multicolumn{2}{|c|}{ Risk } \\
\hline \multirow{4}{*}{ Market Risks } & $\mathrm{CMr}$ & Capital Market risk \\
\cline { 2 - 3 } & $\mathrm{Vr}$ & Valuation risk \\
\cline { 2 - 3 } & $\mathrm{MGRr}$ & Market Growth Rate risk \\
\hline \multirow{4}{*}{$\begin{array}{c}\text { Real Estate } \\
\text { Operating Risks }\end{array}$} & $\mathrm{Or}$ & Operating risk \\
\cline { 2 - 3 } & $\mathrm{Dr}$ & Development risk \\
\cline { 2 - 3 } & $\mathrm{Lr}$ & Leasing risk \\
\cline { 2 - 3 } & $\mathrm{LHr}$ & Leasehold risk \\
\cline { 2 - 3 } & $\mathrm{LVr}$ & Leverage risk \\
\cline { 2 - 3 } & $\mathrm{Tr}$ & Tax risk \\
\hline
\end{tabular}

Market risks can be sub-classified into three categories: Capital Market risk; Valuation risk and Market Growth risk (MGRr), while Operating risk is sub-divided into Operating risk; Development risk (Dr); Leasing risk; Leasehold risk; Leverage risk ; and Tax risk (Tr). We review those to some details. 


\section{(1). Capital Market risk (CMr)}

Capital Market risk is the riskiness of the asset which relates to market capitalization rate and its value reveals whether the asset is priced consistently with capital market prices and rates. It is calculated as the ratio between the average market capitalization rate (MCR) and the asset's capitalization rate (ACR):

$$
\mathrm{CMr}=\frac{M C R}{A C R}
$$

When the market capitalization rate is higher than the project's capitalization rate, the investment riskiness is moderate or aggresive. On the other hand, if the market capitalization rate is lower than the project's capitalization rate, the investment's riskiness is conservative.

\section{(2). Valuation risk (Vr)}

Valuation risk reflects whether an asset is overvalued and will earn less than expected when it matures or is sold in the second market. Factors influencing to $\mathrm{Vr}$ include incomplete or biased data, market volatile and poor data analysis performed by the professional assessing the asset value. Overvalued assets might generate losses for the investors as well as the developers. The value of real estate assets can be generally grouped into two categories: cash flow from contracts (or from the primary market) and resale price. Cash from contracts is more certain and has less risk, while the resale price is more uncertain. In fact, the greater the reliance on the resale activities to result in the desired return, the greater the risk of the asset.

With respect to the resale price, Valuation risk is determined as follows:

$$
\mathrm{Vr}=\frac{N P V R P}{A P}
$$

where NPVRP is the Net Present Value (NPV) of residual (or resale) and AP is the asset's construction/ acquisition cost. If the value of $\mathrm{Vr}<20 \%$, the investment risk can be considered as conservative; when $20 \%<\mathrm{Vr}<60 \%$ the investment is moderate; and when the $\mathrm{Vr}$ value $>60 \%$, it means that the risk is conservative.

\section{(3). Market Growth Rate risk (MGRr)}

Market Growth Rate risk defines the probability that the asset value increases overtime. This risk calculation is used to compare the project value growth rate to the overall market growth rate. If the asset growth rate surpasses inflation rate, the value increase is depending on factors such as capturing below market rent, overheated sales or rental growth expectation. It is necessary to measure the asset growth rate and compare it to the similar property market growth or inflation rate for the purpose to determine whether the asset is being acquired above market growth rates. The MGRr is calculated using the following formula:

$$
\mathrm{MGR} r=\frac{\mathrm{UIRR}-\mathrm{ACR}}{M G R}
$$

where UIRR is the unlevered rate of return, ACR is the initial asset capitalization rate and MGR is the overall market griwth rate. The value if MGRr represents the property investment's growth rate. When MGRr is > $125 \%$, the risk is considered as aggresive, $75 \%$ $<\operatorname{MGRr}<125 \%$, the investment's risk is moderate and it is conservative when the value is $<75 \%$.

The relative value ranges for each investment risk components is classified based on conservative, moderate or aggresive class, as shown in Table 2. The classification ranges is determined based on residential property investor's judgments and real estate experts for certain property market.

\section{(4). Operating risk (Or)}

Operating risk relates to the probability of incurring losses due to changes in demand, input costs, etc. In order to minimize operating risks exposure, operating expenses should be minimized because it will reduce the operating income from the property or will offset the increases in rent thereby reducing the cash flow, and consequently the property value. This risk is mitigated when the tenant shares in the expenses and it is ultimately reduced to zero when the tenant absorbs $100 \%$ of the expenses in the so called triple net lease. Or can be calculated as the ratio of OOR and TOE.

$$
\text { Or }=\frac{O O R}{T O E}
$$

where OOR is the sum of operating and other recoveries paid by the lessee and TOE represents the total operating expenses. If the sharing is above $80 \%$, Or is classified as conservative, otherwise if it is lower than $20 \%$ it is aggressive.

\section{(5). Development risk (Dr)}

Development risk corresponds with land development. It identifies to some extent the probability that any capital expenditure will earn the required rate of return to compensate the investor for the added risk taken, when additional capital is committed to the asset. This risk is incurred when developer considers new development and when a major redevelopment or expansion is considered. Since investing new capital for the expansion or development of an asset should always generate a profit (that in turn should be in line with the risk taken in construction), whenever the profit appears low, the optimal strategy is to renegotiate the cost of construction or require an increase in income to generate an appropriate level of development profit. Dr can be determined as in (6):

$$
\operatorname{Dr}=\frac{(N O I-C C)}{C C}
$$

where NOI is the net operating income and $\mathrm{CC}$ is the construction/renovation cost. NOI is calculated as the investment's Net Present Value. When $\mathrm{Dr}<10 \%$ the risk is aggressive, when $\mathrm{Dr}>20 \%$ it is conservative otherwise it is moderate.

(6). Leasing risk (Lr) 
Leasing risk measures the asset's share of overall market absorption, by comparing the asset performance to the overall market trend. It is the risk that the vacant space will be absorbed at a rate which is slower than projected during the acquisition underwriting of the asset. Whenever the property is not ahead of the market or absorbing its fair share of the market leasing activity, it will affect the overall riskiness. The leasing risk can be determined according to (7):

$$
\operatorname{Lr}=\frac{L U 1 y / M A 1 y}{B V / M V}
$$

where LU1y represents the square meters of rented space in a specific year (1 year Lease Up), MAly is the market demand's absorption relative to that year, BV is the property vacancy and MV is the property's sector-specific market vacancy. When $\mathrm{Lr}<75 \%$ the asset is in the conservative range, when $\mathrm{Lr}>110 \%$ it is in the aggressive range, otherwise the risk is moderate.

\section{(7). Leasehold risk ( $\mathrm{LHr})$}

Leasehold risk measures the probability that the tenant lease terms are above market and that the purchase price is therefore inflated to reflect both the intrinsic real estate value plus the above market leasehold interest. This is the risk to value the above market rent at a higher discount rate than the core asset: if the market rents are lower than the project's ones, in order to ensure that the investment well performs and mitigate risk, it might be necessary to adopt a higher capitalization rate, to adjust the asset's value to market values. $\mathrm{LHr}$ is measured by the ratio between the Gross Rental Income and the average market rents (MR).

$$
\mathrm{LHr}=\frac{G R I}{M R}
$$

where GRI is the gross rental income and MR is the market average rent. When $\mathrm{LHr}<85 \%$ the risk is conservative, while when $\mathrm{LHr}>115 \%$ the risk is aggressive. The value in between means that the risk is moderate.

\section{(8). Leverage risk (LVr)}

Leverage risk is the risk where the cost of debt exceeds the return on the asset to be acquired. Leverage creates risk as the lender has a priority position in the repayment of the outstanding loan balance, upon sale or liquidation of the asset and it is related to the percentage of equity and debt and the related cost of capital. It is calculated as follows:

$$
\mathrm{LVr}=\frac{U I R R}{K D}
$$

where UIRR is the unlevered internal rate of return taken in a certain year or period, and KD is the cost of leverage. When $\mathrm{LVr}>115 \%$ the asset is in the conservative range, when $\mathrm{LVr}<100 \%$ it is in the aggressive range, otherwise the risk is moderate. LVr may also arise when the cost of debt, including the amortization of the debt, exceeds the cap rate upon acquisition. In this case there will be a negative leverage in the early years of the property operations, but negative leverage may run out as the annual income an annual cap rate from the property increases and exceeds the loan constant (KD will be less than the Internal Rate of Return expected from the asset operation). When a loss occurs, the deficit becomes magnified based on the ratio of leverage, or debt, added to the trade. Otherwise, when the trade is successful, the payoffs are similarly amplified. The ratio of financial leverage and risk can be determined based on the size of the loan in relation to the value of total assets overseen by an investor. Consequently leverage may amplify the rate of return for an asset, in a positive or negative direction. The optimal investment strategy is to lever or amplify the return by the use of debt when there is a positive leverage. This risk category is generally a primary consideration taken by lenders.

\section{(9). Tax risk (Tr)}

Tax risk relates to the potential that a chosen action or activity, or the failure to take an action or pursue an activity, will lead to a tax outcome that is different than initially expected. This risk can obviously be determined whenever the valuer knows the taxation level of the entrepreneur who is involved in real estate investment. We do not consider this risk and we are not addressing the issue in this paper because that varying levels of risk accompany tax strategies.

Table 2 summarizes for each risk component the relative value ranges according to which risks can be classified as Conservative, Moderate or Aggressive. These classification ranges is based on judgments by real estate institutional investors and industry experts in Italy [7].

Table 2. Classification of risk value ranges.

\begin{tabular}{|l|l|l|l|}
\hline \multirow{2}{*}{ Risk } & \multicolumn{3}{|c|}{ Riskiness value ranges } \\
\cline { 2 - 4 } & Conservative & Moderate & Aggresive \\
\hline $\mathrm{CMr}$ & $<90 \%$ & $90-110 \%$ & $>110 \%$ \\
\hline $\mathrm{Vr}$ & $<20 \%$ & $20-60 \%$ & $>60 \%$ \\
\hline $\mathrm{MGRr}$ & $<75 \%$ & $75-125 \%$ & $>125 \%$ \\
\hline $\mathrm{Or}$ & $>80 \%$ & $20-80 \%$ & $<20 \%$ \\
\hline $\mathrm{Dr}$ & $>20 \%$ & $10-20 \%$ & $<10 \%$ \\
\hline $\mathrm{Lr}$ & $<75 \%$ & $75-110 \%$ & $>110 \%$ \\
\hline $\mathrm{LHr}$ & $<85 \%$ & $85-115 \%$ & $>115 \%$ \\
\hline $\mathrm{LVr}$ & $>115 \%$ & $100-115 \%$ & $<100 \%$ \\
\hline
\end{tabular}

\section{The Case Study: Rental Apartment}

This paper is based on a quantitative case study conducted on a leased apartment project located in Jalan Jagir Wonokromo - Surabaya. Although the project is surrounded by dense existing houses, the location can be considered as premium in Surabaya. The data were obtained from the developer. The project of which construction was started on 2017 consists of a new residential complex, includes 6 apartment towers, 1 level of basement and 5 levels of podiums, covers the total area of 3,1 hectares. The project provides parking areas and 
retail business units (ruko) located in the basement and podiums. This project is also equipped with amenities and children playground in the sixth floor and sky garden in the $26^{\text {th }}$ floor. They planned to develop the project in 6 phases started in 2017 and was expected to complete in 2025. In order to be able to obtain separate construction cost stages, the buildings are separated by construction joints. For the purpose on this study, we consider phase 1, consisting of 1 tower namely Tower A and its related facilities and infrastructures. It was structured into 46 floors with total of 50,971 sq. meter (Table 3).

Table 3. Project Data.

\begin{tabular}{|r|l|r|}
\hline No & Project Configuration & \multicolumn{1}{l|}{ Tower A } \\
\hline 1 & Land Area & 8,773 sq. $\mathrm{m}$ \\
\hline 2 & Development Area & 3,260 sq. $\mathrm{m}$ \\
\hline 3 & Infrastructure Area & 5,513 sq. $\mathrm{m}$ \\
\hline 4 & Building Coverage Ratio & $37.16 \%$ \\
\hline 5 & Floor Area Ratio (KLB) & 8.29 \\
\hline 6 & Net Floor Area & 31,829 sq. $\mathrm{m}$ \\
\hline 7 & Semi Gross Floor Area & 38,424 sq. $\mathrm{m}$ \\
\hline 8 & Gross Floor Area & 50,971 sq. $\mathrm{m}$ \\
\hline 9 & Efficiency (SG/GFA) & $75.4 \%$ \\
\hline 10 & Number of units & 1,040 unit \\
\hline 11 & Number of retail units & 47 \\
\hline
\end{tabular}

The project was offered in 5 types of apartment units namely Studio A, Studio B, 1 bedroom, 2 bedrooms and loft with different sizes described in Table 4 and Table 5.

Table 4. Unit Configuration.

\begin{tabular}{|l|c|c|}
\hline Type & Quantity (unit) & Overall (unit) \\
\hline Studio A & 240 & 240 \\
\hline Studio B & 20 & 20 \\
\hline 1BR & 572 & 572 \\
\hline 2BR & 202 & 202 \\
\hline Loft & 6 & 6 \\
\hline Total & 1,040 & 1,040 \\
\hline
\end{tabular}

Table 5. Unit Size.

\begin{tabular}{|l|c|c|}
\hline Type & Size (sq.m) & Average (sq.m) \\
\hline Studio A & 25.94 & 25.94 \\
\hline Studio B & 32.17 & 32.17 \\
\hline 1BR & 35.32 & 35.32 \\
\hline 2BR & 52.08 & 52.08 \\
\hline Loft & 138.50 & 138.50 \\
\hline
\end{tabular}

We then collected the financial data to do the risk assessment of the project. It can be described as follows: The construction costs amount IDR 460.2 billion, and the total development cost was IDR 681.5 billion including land acquisition, design, permit and construction cost. The project will be completed within 3 years, therefore it will start to generate income in 2019 when the units are ready for rent. The tower was scheduled to have 14 year investment period starting from the launching time in 2019 , and was expected to get a resale value of IDR 820.6 billion in 2032. From the launching time until 2019, the sales was assumed to book $60 \%$ of the total units and will increase to $75 \%$ within 3 years from the commencement of construction, $85 \%$ within 7 years and at the end of investment year the occupancy was expected to achieve $95 \%$. The units' average rental price started with IDR $1,400,000$ per sq. meter per year, and will grow up of average $20 \%$ in every 2 years, while the retail unit's rental price will start with IDR 2,500,000.

A syndicate of national banks has agreed to fund the project. They required the developer to provide $30 \%$ of the total investment cost, while they fund the rest with an initial interest rate of $9 \%$ a year. In the feasibility study, the developer set the minimum attractive rate of return (MARR) of $16 \%$, the rate of the Market Growth was $4 \%$, while the capitalization rate of $12 \%$ was assumed for the similar projects. Using those economic data and assumptions, the cash flow analysis showed that the NOI was IDR 271.4 billion, the NPV was 95.4 billion, UIRR was $14 \%$ and the IRR was $22.8 \%$.

Based on the data and projections, we framed the investment decision using risk assessment model described in the previous section. The results of the application are presented as follows:

\section{(1). Capital Market Risk (CMr)}

To determine the CMr at a certain year, we assumed that the market capitalization rate (MCR) for similar projects was $12 \%$. Now that the value of the project is IDR 820.6 billion and the net operating income is IDR 271,4 billion, we obtain that the asset capitalization rate (ACR) was $33 \%$, and at the first year of the project, the capital market risk is $36 \%$, which means that the risk is conservative and therefore acceptable. It is worthwhile to note that $\mathrm{CMr}$ is depending on the resale price which was a projection. If the assumption was too overestimated, we have to be careful of the result. The $\mathrm{CMr}$ is also sensitive of the market growth rate, therefore in times of financial or market crisis, the higher MGR estimate will cause an unacceptable risk in regards to capital market.

\section{(2). Valuation Risk (Vr)}

The expected property residual value at the end of the investment period is IDR 820.6 billion and the present value of the number is IDR 88.5 billion. Since the total development cost was IDR 681.5 billion, we then calculate the $\mathrm{Vr}$ by dividing the present value of the residual price with the total development cost, which is $13 \%$. Based on the result we conclude that the $\mathrm{Vr}$ is conservative. As we described previously, the higher the residual value of the property, the asset is perceived as risky. Therefore we have to collect as much as information to make a reliable projection and to asses risk, especially when the investment period is relatively long and yet very unpredictable.

\section{(3). Market Growth Risk (MGRr)}

Since the unleveraged rate of return (UIRR) was $14 \%$ and the initial asset capitalization rate (ACR) was $33 \%$, while 
the market growth rate was $4 \%$, the simulation showed that MGRr was $50 \%$ which reflects that the market growth rate risk is within conservative range. It is worth noting that if the asset capitalization rate reduced by around 3\% (i.e the ACR becomes 9\%), the MGRr will be $125 \%$ and the investment's risk becomes aggressive (around 125\%). This means that MGRr is sensitive to the asset capitalization rate. In other word, we have to be careful in estimating the income coming from rental. Referring to the definition, the MGRr is also sensitive to the market growth rate, therefore when the project was developed under market uncertainty it is essential to make a reasonable estimate and properly address the risk.

\section{(4). Operating Risk (Or)}

The property contract agreement is determined based on allocation risk of operating expenses between the developer and the lease. In this study, we estimated the initial service charge rate generated from the similar project, which was average IDR 17,000 per square meter per month plus $10 \%$ sinking fund. On the other hand, the operating cost was IDR 10,000 per square meter per month. Both income and expenses started from 2019 until 2032. From the simulation, we find that the operating risk is $112 \%$ and is therefore conservative. In such an economic instability situation, the lessee will probably reluctant to pay the amount and demanding for less, while the operating cost raised, meaning that the income projection was too overestimated and the operating risk will fall between moderate or aggressive.

\section{(5). Development Risk (Dr)}

Development risk relates to the competitiveness of the market that requires the management team to do some renovation on the property from time to time.

The development team has been planning to do some renovation in some units with total floor area of 5,200 sq. meter. The construction cost estimate was IDR. 2,000,000 per sq. meter so the total cost will be IDR. 10.4 billion. If the upgrading works will increase rental rate by IDR. 490,000 per sq. meter per month, they will reap about IDR. 15.3 billion. The net profit is equal to IDR. 4.9 billion and the development risk is equal to $47 \%$. This implies that the decision to upgrade the property will generate a conservative risk. From the definition and the exercise it is clear that the risk is affected by the projection of rental rate increment. When the project is under market volatility and the prediction is uncertain, the value of net operating income tends to decrease and the development will be more risky (either in moderate or aggressive range).

\section{(6). Leasing Risk (Lr)}

Leasing risk is a very important parameter to assessing risk of apartment development since it strongly correlates with market absorption. Market might be very complex and yet unpredictable so that this is one critical source of uncertainty.
According to Surabaya Property Market Report in H1 of 2017 [13], the expected market stock for rental apartment in Surabaya is about 924. Further, they predicted that in the same period, the apartment market vacancy will slightly rise up by 20,000 sq. meter to 53,600 or 1,340 units of 40 sq. meter each. In the feasibility analysis, the developer has set the absorption for tower A in the same year was 420 units of average 40 sq. meter. Since the occupancy was 624 units, consequently the rest (i.e. 420 units) will be vacant. We can now calculate the leasing risk using the formula described previously. The risk equals to around $215 \%$, which means that the risk is very aggressive.

It is also critical to evaluate the result for an investment decision, since the occupancy target was optimistic, despite of the fact that the market vacancy was relatively high. Should the projected space absorption not meet the target and/or the market vacancy is higher than the estimate, the risk will be higher. In this regard, we are required to modify the scenario by lowering cash inflow and slowing demand.

\section{(7). Leasehold Risk (LHr)}

To calculate this risk parameter, again we refer to Surabaya Property Market [10], where it projected the apartment average market rent of IDR. 2,700,000. Since the gross rental income estimate for this phase was IDR. $1,650,000$, the leasehold risk comes to $61 \%$. It is conservative as long as the rental term is above market, but there is still a potential risk if we are over optimistic over the term, especially when the market is volatile.

\section{(8). Leverage Risk (LVr)}

According to the exercise, the UIRR was $14 \%$ and the KD (i.e. interest rate) was $9 \%$. The LVr is therefore equal to $156 \%$. This type of risk relates to the use of loan that results in leverage and yet cost of leverage. When the economic condition is not preferable, the floating interest rate might raise up and the risk will fall below $100 \%$. It is not conservative anymore.

It is important to thoroughly assess a project's anticipated net operating income, because it is this amount that will be required to cover the debt service. The risk of shortfall will increase when there is more debt on the property.

From the exercises, the whole risk assessment results from the case can be summarized, as shown in Table 6 . The results show that most of the investment riskinesses are conservative, therefore they can be considered as low risks, except for leasing risk which falls within aggresive range.

Table 6. Apartment Risk Values

\begin{tabular}{|l|c|c|}
\hline Risk & Value & Category \\
\hline $\mathrm{CMr}$ & $36 \%$ & Conservative \\
\hline $\mathrm{Vr}$ & $13 \%$ & Conservative \\
\hline $\mathrm{MGRr}$ & $50 \%$ & Conservative \\
\hline
\end{tabular}




\begin{tabular}{|l|c|l|}
\hline Or & $112 \%$ & Conservative \\
\hline Dr & $47 \%$ & Conservative \\
\hline Lr & $215 \%$ & Aggressive \\
\hline LHr & $61 \%$ & Conservative \\
\hline LVr & $156 \%$ & Conservative \\
\hline
\end{tabular}

Nevertheless, since leasing risk is a parameter strongly associated with lease transaction, market absorption and the supply side of the property, careful attention must be paid before taking investment decision. In times of market slow-down yet uncertain, those indicators are paramount and may have strong negative impact in the return of the project. Even though the financial analysis proved to be a positive net present value, the investment can be considered as unacceptable. If so, it is important to conduct deeper market study and explore alternatives to minimize the negative impact of the underlying risk.

It is also worthwhile to note that the proposed approach provide different perspective of assessing risk in property development from what the conventional tools did. Despite the fact that the net operating income was positive and the internal rate of return was acceptable, the result of this study revealed another potential risk which can not be identified by the previous mentioned indicators; it does not automatically mean that the development is risk free.

\section{Conclusion}

There are considerable factors beyond the conventional model that may cause adverse impacts on the project goals. The risk measurement approach proposed in this paper can be beneficial in the decisionmaking process and establishing strategies in risk management. Each value is related to a specific risk measure, so that a specific risk component can be managed to an acceptable level.

When the market is unpredictable and/ or the future is uncertain, it is advised to investigate the project feasibility when they do not rely on the existing risk procedures and the future of the investment. The final decision will depend on their risk attitude. In this regard, this study offer an alternative operational approach to address risk and uncertainty that may enhance a more comprehensive decision-making process in apartment investment.

Due to some limitations in this study, especially in utilizing parameters of risks, it was recommended to conduct further studies in order to obtain novel risk assessment tools which is more applicable locally.

We would like to express our gratitude to the Chair and the Committee for the opportunity to participate in the $4^{\text {th }}$ International Conference on SCESCM.

\section{References}

1. K.Jan R, L.Gieyoung, Econ.Mod. Fundamentals and rational bubbles in the Korean housing market: A modified present-value approach, 59, 1, (2016)

2. Bank Indonesia, Survey harga property residensial triwulan I - 2009, 5, (2009)
3. Qian W.L, Real Est Econ, Why do sellers hold out in the housing market? An option based explanation, 41, 384-417 (2013)

4. Bank Indonesia, Survey harga property residensial triwulan I - 2010, 5, (2010) [in Indonesian].

5. Mike E.M, Real estate development: principles and process, $5^{\text {th }}$ Ed, Urban Land Institute (2015)

6. P.J.Byrne, D. Cadman, Risk, uncertainty and decision-making in property development, $2^{\text {nd }} \mathrm{Ed}$, Taylor and Francis (1996)

7. C. D'Alphaos, R. Canesi, WSEAS T. on Business and Econ, Risk assessment in real estate investment in times of global crisis, 11, 369-378 (2014)

8. A. Adair, N. Hutchison, J. of. Prop. Inv, The reporting of risk in real estate appraisal property risk scoring, 23, 254-268 (2005)

9. O. Armaneri, G. Ozdagoglu, O. Yalcinkaya, J. of. Comp. and App. Math, An integrated decision support approach for project investors in risky and uncertain environments, 234, 2530-2531 (2010)

10. F. Choobineh, A.Behrens, J. of the Op. Res. Soc, Use of intervals and possibility distributions in economic analysis, 43, 907-918 (1992)

11. C.S. Park, Contemporary Engineering Economics, $3^{\text {rd }}$ ed., (2002)

12. The European Group of Valuers' Associations, European Valuation Standards 2012, $7^{\text {th }}$ Ed.(2012)

13. Colliers International, Surabaya property market report H1-2017, Colliers half year report (2017). 